\title{
Kearifan Lokal Masyarakat Dalam Menjaga Kelestarian Hutan Dan Mengelola Mata Air di Desa Watowara, Kecamatan Titehena Kabupaten Flores Timur Nusa Tenggara Timur
}

\author{
Ignasius Suban Angin ${ }^{1^{*}}$, Sunimbar ${ }^{2}$ \\ 1,2 Program Studi Pendidikan Geografi Fakultas Keguruan dan IImu Pendidikan \\ Universitas Nusa Cendana Kupang \\ * ignasiusubanangin@gmail.com
}

\begin{abstract}
Abstrak
Tujuan dari penelitian ini adalah: (1) mengetahui dan mendeskripsikan kearifan lokal masyarakat Desa Watowara dalam menjaga kelestarian hutan dan mengelola mata air, (2) mengetahui dan menganalisis dampak kearifan lokal masyarakat terhadap kelestarian hutan dan terhadap keberadaan sumber mata air di Desa Watowara. Metode penelitian yang digunakan adalah wawancara mendalam dengan teknik bola salju kepada informan kunci meliputi tetua adat, juru kunci hutan, Kabelenraya, dan masyarakat Desa Watowara lainnya. Data dianalisis menggunakan teknik deskriptif kualitatif dengan pendekatan ekologis.

Hasil penelitian menunjukkan bahwa kearifan lokal masyarakat Desa Watowara dalam menjaga kelestarian hutan dan mengelola mata air berupa upacara adat, berbagai anjuran dan larangan lokal serta mitos. Kearifan lokal ini memberikan dampak positif terhadap Desa Watowara, diawali dengan tumbuhnya kesadaraan masyarakat dalam menjaga kelestarian alam. Selain itu, melalui Paugota (Baololong) dan gemohing masyarakat melakukan gotong-royong membersihkan desa, mata air, dan menanam pohon. Melalui kearifan lokal, masyarakat berhasil menjaga kelestarian hutan dan mata air, mencegah kegundulan hutan, bencana (erosi, banjir), dan terhindar dari masalah kesulitan air.
\end{abstract}

Kata kunci: kearifan lokal, kelestarian hutan, pengelolaan mata air, Desa Watowara.

\section{Local Wisdom of the Community in Maintaining Forest Conservation and Managing Springs in Watowara Village, Titehena District, East Flores Regency, East Nusa Tenggara Ignasius Suban Angin ${ }^{1^{*}}$, Sunimbar ${ }^{2}$ \\ 1,2 Geography Education Department Faculty of Teacher Training and Education University of Nusa Cendana kupang}

\footnotetext{
Abstract

The goals of this research are: (1) to observe and to describe Watowara Village's local wisdom in maintaining forest sustainability and managing the springs, (2) to find out and to analyze the impacts of their local wisdom toward forest preservation and the existence of the springs. The method of this research is in-depth interview by using snowball sampling technique to the key informans, such as Kebelenraya of the indigenous village of Watowara, key person of Kayotale, and several people in Watowara Village. The data was analyzed by using qualitative descriptive analysis with ecological approach.

The results of this research show that Watowara Village's local wisdom in maintaining the sustainability of the forest and managing the springs are expressed by conducting traditional ceremonies, the various local recommendations and Kearifan Lokal Masyarakat Dalam Menjaga Kelestarian Hutan... Ignasius Suban Angin, Sunimbar
} 
restrictions, and the myths. This local wisdom affected the conservation of existing forest and springs in Watowara Village positively. Commencing with the growth of the sense of belonging and responsibility towards the preservation of nature. Besides, with the Paugota Lewotana (Baololong) dan Gemohing ceremony the society do some mutual activites like cleaning up the village, springs, and planting trees. Through their local wisdom they managed to maintaining the forest sustainability and springs, preventing denuded forest, minimalizing the potential disasters (erosion and flood), and avoided from some water issues.

Key words: local wisdom, forest sustainability, spring management, Watowara Village.

\section{Pendahuluan}

Desa Watowara, Kecamatan Titehena, Kabupaten Flores Timur, NTT, memiliki wilayah hutan yang dikelola secara adat oleh masyarakat setempat, yaitu Hutan Wailihang. Kawasan Hutan Wailihang pada tahun 1970-an pernah menjadi daerah gersang dan sering terjadi bencana kekeringan dan erosi. Namun, berkat kesadaran masyarakat setempat secara swadaya dengan menanam segala tanaman yang ada, maka terciptalah Hutan Waihilang yang salah satu tujuannya untuk menjaga sumber mata air yang terdapat di dalam hutan tersebut. Simbol kekeramatan mulai diciptakan untuk menjaga keutuhan ekosistem yang terbentuk, dengan mitos dan tahayul sebagai perspektif masyarakat lokal. Selama bertahuntahun masyarakat setempat menanamkan suatu bentuk kearifan lokal untuk menjaga hutan tersebut. Alhasil Hutan Wialihang dan sumber mata air yang ada tidak pernah terusik oleh masyarakat di sekitarnya.

Kearifan lokal menurut Sumarmi dan Amirudin (2014) merupakan suatu bentuk tata nilai, sikap, persepsi, perilaku dan respon suatu masyarakat lokal dalam berinteraksi pada suatu sistem kehidupan dengan alam dan lingkungan tempat tinggalnya secara arif. Selanjutnya, dijelaskan bahwa kearifan lokal dapat berupa strategi kehidupan untuk pengelolaan alam semesta dan menjaga keseimbangan ekologis terhadap berbagai bencana dan kendala yang ditimbulkan dari alam maupun manusia.

Pengelolaan hutan dan mata air dengan berbasis kearifan lokal yang telah dilaksanakan secara turun-temurun oleh masyarakat Desa Watowara, diharapkan dapat menjaga lingkungan setempat, khususnya hutan dan sumber mata air Wailihang yang ada. Berbagai bentuk kearifan lokal ini juga merupakan wujud rasa syukur masyarakat Desa Watowara kepada Sang Pencipta (Lera Wulan Tanaekan)

Kearifan Lokal Masyarakat Dalam Menjaga Kelestarian Hutan... 
atas sumberdaya alam yang melimpah dan menjadi salah satu bentuk konservasi alam dan pelestarian budaya di Desa Watowara.

Adapun tujuan dilakukan penelitian ini adalah: (1) mengetahui dan mendeskripsikan kearifan lokal masyarakat dalam menjaga kelestarian hutan dan mengelola mata air di Desa Watowara; dan (2) mengetahui dan menganalisis dampak yang ditimbulkan dari kearifan lokal yang dilakukan masyarakat terhadap kelestarian hutan dan terhadap keberadaan sumber mataait Wailihang di Desa Watowara.

\section{Metodologi}

Daerah penelitian berlokasi di Desa Watowara, Kecamatan Titehena, Kabupaten Flores Timur, Provinsi Nusa Tenggara Timur. Pemilihan lokasi ini didasarkan karena Desa Watowara merupakan daerah yang masih melaksanakan dan memegang teguh kearifan lokal sebagai salah satu bentuk pelestarian lingkungan, khususnya kearifan lokal masyarakat dalam menjaga kelestarian hutan dan mengelola mata air.

Penelitian ini merupakan penelitian kualitatif dengan melakukan tahapan wawancara mendalam (in-depth interview) untuk memperoleh data primer di lapangan. Sedangkan data sekunder, didapatkan dari berbagai referensi seperti buku, jurnal, penelitian terdahulu, yang digunakan untuk mengetahui referensi terkait kearifan local dan keadaan geografis, kondisi fisik, dan demografis daerah penelitian.

\section{Cara Pengumpulan Data}

Tinjauan Lapangan

Tinjauan lapangan dilakukan untuk mengumpulkan sejumlah data secara langsung di lapangan (data primer) sekaligus mengamati secara langsung kondisi di lapangan yang terkait dengan kearifan lokal masyarakat Desa Watowara. Hal yang dipersiapkan sebelum melakukan tahap ini adalah membuat kriteria pencakupan informan dan interview guide (pedoman wawancaca), yaitu pedoman pertanyaan yang hanya berisi isu-isu pokok yang diteliti dan bersifat tidak terstruktur. Pedoman wawancara dalam penelitian ini mencakup aspek sebagai berikut: (1) aspek sejarah di Desa Watowara; (2) aspek kearifan lokal Desa Watowara (latar belakang, bentuk, 
dan dampak); dan (3) aspek budaya Desa Watowara yang berperan terhadap lingkungan.

\section{Wawancara Mendalam}

Tahap wawancara mendalam merupakan teknik untuk memperoleh informasi dengan bertanya langsung kepada informan yang menguasai objek penelitian sesuai dengan topik penelitian yang dilakukan (Singarimbun, 2012). Tahapan wawancara disertai dengan mencatat uraian jawaban yang dipaparkan oleh informan. Selain itu, dilengkapi pula dengan pengambilan gambar terkait objek penelitian untuk mendukung dan memperkuat hasil penelitian. Wawancara mendalam dilakukan sesuai dengan pedoman wawancara yang telah dibuat dan dihentikan apabila informasi yang diperoleh telah jenuh.

\section{Informan Penelitian}

Informan pertama pada penelitian ini dipilih secara purposive oleh peneliti. Sedangkan, informan selanjutnya dipilih dengan cara bola salju (snowball sampling) sesuai dengan arahan dan rekomendasi dari informan sebelumnya. Informan pertama merupakan orang yang dianggap paling mengetahui kondisi dan masyarakat setempat sehingga dapat memberikan informasi sesuai tujuan penelitian dan memberikan arahan terkait informan selanjutnya. Daftar informan dalam penelitian ini, dilihat pada Tabel 1.

\section{Tabel 1. Informan Penelitian}

\begin{tabular}{|c|c|c|}
\hline No. & Peran & Peran di Masyarakat \\
\hline 1. & Informen 1 & Kepala Desa \\
\hline 2. & Informan 2 & $\begin{array}{l}\text { Tetua adat Desa Watowara, juru kunci Baololong dan } \\
\text { upacara adat di Desa Watowara (Warga Dusun Lato) }\end{array}$ \\
\hline 3. & Informan 3 & Peguyuban kelompok Baololong \& Gemohing \\
\hline 4. & Informan 4 & $\begin{array}{l}\text { Juru Kunci Kebelenraya Hutan Waihilang/Warga Dusun } \\
\text { Lato }\end{array}$ \\
\hline 5. & Informan 5 & Peguyuban Kayotale Air Hutan Wailihang \\
\hline 6. & Informan 6 & Kebelenraya Lewotana \\
\hline 7. & Informan 7 & $\begin{array}{l}\text { Kebelenraya Lewotana Pemangku hak ulayat Hutan } \\
\text { Wailihang }\end{array}$ \\
\hline 8. & Informan 8 & Masyarakat Dusun Lato \\
\hline 9. & Informan 9 & Masyarakat Dusun Lato \\
\hline 10. & $\begin{array}{l}\text { Informan } \\
10\end{array}$ & Anggota peguyuban pengelola air Wailihang \\
\hline
\end{tabular}

Kearifan Lokal Masyarakat Dalam Menjaga Kelestarian Hutan... 


\section{Cara Pengolahan Data}

Cara pengolahan data meliputi tahap reduksi, klasifikasi dan penyajian data. Reduksi data merupakan proses seleksi, pemfokusan, penyederhanaan, dan abstraksi. Langkah ini dilakukan dengan memilih informasi yang telah dikumpulkan dari hasil wawancara terkait kearifan lokal masyarakat Desa Watowara, khususnya dalam menjaga kelestarian hutan dan mengelola mata air. Informasi dari hasil wawancara di lapangan dibaca kembali.

Tahap klasifikasi bertujuan untuk mengelompokkan data yang merujuk kepada pertanyaan penelitian dan unsur-unsur yang terkandung dalam penelitian ini. Melalui tahapan klasifikasi data diperoleh beberapa kelompok kearifan lokal berupa upacara adat, anjuran dan larangan lokal, dan mitos. Kemudian data disajikan dalam bentuk deskripsi, tabel, kutipan wawancara, dan gambar untuk mendukung hasil penelitian.

\section{Analisis Data}

Analisis data dilakukan terhadap data primer maupun data sekunder dengan menggunakan teknik analisis deskriptif kualitatif. Penelitian ini menggunakan pendekatan ekologis, sehingga hasil analisis selama observasi lapangan dan data yang telah diperoleh dapat menggambarkan serta menunjukkan analisis yang lebih sistematik tentang peranan elemen lingkungan terhadap pola kegiatan manusia yang difokuskan pada suatu wilayah khusus dan bersifat human oriented.

Pendekatan ekologis yang dirasa lebih tepat untuk penelitian terkait kearifan lokal adalah human behavior-environment interactions. Pendekatan tersebut fokus terhadap keterkaitan persepsi yang dibangun oleh manusia dalam melakukan kegiatan-kegiatan sesuai dengan perilaku budaya (kultural), sosial, dan ekonomi dalam interaksinya dengan lingkungan sekitar (Yunus, 2010). Dalam hal ini terkait fokus pengamatan terhadap masyarakat Desa Watowara yang masih memegang teguh Lerawulan Tanaekan, Kewokeng, Lewotana, Nubanara dan prinsip leluhurnya, sehingga melahirkan berbagai bentuk kearifan lokal masyarakat dalam menjaga kelestarian hutan mata air yang ada. 


\section{Pembahasan}

Potensi Sumber Mata air di Desa Watowara, Kecamatan Titehena

Desa Watowara, Kecamatan Titehena memiliki satu titik sumber mata air yang terdapat dalam wilayah Hutan Adat Wailihang, jaraknya sekitar 1 kilometer, berada di wilayah perbukitan. Sumber mata air Wailihang yang terdapat di wilayah Desa Watowara dimanfaatkan oleh sekitar $315 \mathrm{KK}$ untuk memenuhi kebutuhan air domestik di Desa Watowara. Sementara sekitar 30 KK berada di Dusun Bejawa, untuk memenuhi kebutuhan air domestiknya memanfaatkan sumur gali.

Lokasi titik sumber mata air biasanya berasosiasi dengan pohon besar didekatnya. Area ini lebih sering disebut masyarakat lokal dengan sebutan Waimatang. Waimatang Wailihang, setelah peristiwa gempabumi tektonik 1992 (gempabumi Flores 1992) dilengkapi dengan bangunan bak penampungan, kemudian dilengkapi pipa untuk mengalirkan mata air ke bak-bak tampungan per dusun, lalu dialirkan ke rumah-rumah warga. Menurut Informan 5, debit mata air Wailihang yang melayani masyarakat di Desa Watowara rata-rata cukup deras dan selalu mengalir sepanjang tahun dan tidak pernah mengering. Mata air tersebut memiliki debit sekitar 3 liter/detik. Fluktuasi debit terjadi sekitar September hingga Oktober.

Secara kualitatif menggunakan indera perasa dan pembau menunjukkan bahwa mata air Wailihang yang melayani kebutuhan domestik penduduk Desa Watowara, memiliki kondisi yang baik dengan ketersediaan yang melimpah. Hal ini ditandai dengan air tidak memiliki warna, rasa, dan bau. Sehingga air dapat dimanfaatkan untuk segala kebutuhan masyarakat setempat seperti memasak, minum, mandi, mencuci, dan menyiram tanaman di halaman rumah. Sumber mata air Wailihang tidak pernah kering.

Kearifan Lokal Masyarakat dalam Menjaga Kelestarian Hutan dan Mengelola Mata air di Desa Watowara

Upacara Baololong

Upacara Baololong adalah salah satu kearifan lokal di Desa Watowara yang masih dipertahankan, bahkan terus dilestarikan hingga sekarang. Baololong, ritual 
adat, ditujukan kepada Lera Wulan Tanaekan (Ilahi, menurut religi asli masyarakat Watowara), kepada leluhur (Kewokokeng), dan Nitung Lolong, penjaga hutan dan matair Wailihang. Upacara Baololong melibatkan seluruh masyarakat di Desa Watowara yang mencakup seluruh elemen di masyarakat, dimana tiap-tiap dusun yang ada di Desa Watowara diharuskan untuk membawa sedekah. Sedekah yang dimaksud adalah berupa Nasi beserta lauk pauk (daging ayam, terutama hati ayam) untuk masing-masing kepala keluarga. Sedekah yang dibawa disebut mati.

Upacara baololong hutan dan matair Wailihang meliputi beberapa rangkaian kegiatan yang disertai dengan berbagai ritual adat, seperti pau gota Lewotana, dan neing kewokekeng (beri makan kepada leluhur), gemohing (budaya gotong royong), membersihkan desa, bersih matair Wailihang, disertai dengan doa-doa yang dilengkapi dengan persembahan sesajen.. Lokasi tempat persembahan dikenal dengan sebutan Nubanara yang berada di bagian hulu Hutan Wailihang. Upacara Baololong dilakukan setahun sekali setelah masa panen padi dan jagung. Menurut Informan 4, hari ditentukan oleh perembukan antara kebelen raya, tetua adat (guyub kelakeheng lewotana). Pernyataan infoman 3, sebagai berikut:

Baololong itu dilaksanakan satu tahun sekali Ama, setelah masa panen (padi \& jagung), waktunya tergantung kesepakatan guyub kebelen lewotana. Tujuan ritual tersebut adalah penghormatan terhadap Lera Wulang Tana Ekang. (Matahari, Bulan, Bumi), penghormatan kepada leluhur (kewokokeng), glete glouk Lewotana (pembersihan kampung halaman dari marabahaya). Nong, Lera itu artinya Matahari, penjaga kehidupan, simbol Bapak, Wulang, artinya Bulan, pemberi penerangan, Tana Ekang, itu Bumi dan sumberdaya alam, simbol lbu, sebagai sumber kehidupan. Ritual ini mengandung makna magis-religius, dan mengandung filosofis masyarakat, yaitu harmonis dengan Ilahi, harmonis dengan leluhur, harmonis dengan sesama manusia, dan harmonis dengan alam dan isinya (tanah, hutan, dan air).

\section{Upacara Glete Gluok Lewotana}

Lewotana adalah sumber kekuatan masyarakat Desa Watowara. Upacara glete gluok Lewotana (bersih Lewotana), agar dijauhkan dari marabahaya (yang tidak kelihatan), dijauhkan dari penyakit (yang kelihatan).

Upacara Nitung Lolong dan Puduk

Ritual ini dilakukan pada hutan dan mata air (waimatang). Ritual ini bertujuan untuk memberikan peringatan kepada penjaga tanah, hutan, dan sumberair, supaya sumberdaya lahan, sumberdaya hayati, sumberdaya air, supaya tetap lestari. Hal ini 
mempengaruhi psikogeografi masyarakat setempat supaya tidak boleh merusak lahan, tidak boleh menebang hutan, sehingga mata air tetap lestari.

Pada upacara ini, dilakukan pembersihan mata air, yang dilakukan oleh Kebelenraya, Kebelen Lewotana, guyub Kayotale, Kepala-kepala suku, Sementara, pada saat yang sama, masyarakat biasa bergotong royong membersihkan fisik desa (budaya gotong royong, disebut gemohing).

Anjuran dan Larangan Lokal

Kearifan lokal yang ada dan hidup di Desa Watowara tidak terlepas dengan adanya berbagai anjuran dan larangan lokal yang telah disepakati bersama sebagai suatu aturan adat di tengah-tengah masyarakat Desa Watowara. Masyarakat menganggap bahwa seluruh anjuran dan larangan yang berlaku harus selalu diperhatikan dan dilaksanakan. Berikut adalah pernyataan informan 1 mengenai anjuran dan larangan yang tidak boleh dilanggar oleh masyarakat, khususnya terkait dengan menjaga kelestarian lingkungan (hutan, tanah dan air) di Desa Watowara:
Aturan yang sudah dari Kewokokeng (leluhur) dulu harus terus dilakukan, karena menghormati leluhur sini, itu kan sudah jadi adat nya Desa Watowara juga, Ama. Kalau yang tidak boleh dilakukan itu kalau dilanggar bisa tertimpa hal buruk atau musibah. Misalnya, menebang kayu di Hutan Wailihang buat bangun rumah nanti rumahnya bisa rusak sampe roboh.". Ama hutan itu tempat tinggal Nitung Lolong dan tempat tinggal Puduk. Mata air tidak boleh dirusakan, karena ada penjaganya, kalau melanggar berarti mati taruhannya (Kutipan wawancara dengan Informan 2).

Anjuran dan larangan lokal ini selalu dipegang teguh oleh masyarakat Desa Watowara dalam memaknai alam dan berinteraksi dengan Hutan dan sumber mata air Wailihang. Nasihat-nasihat leluhur ini juga terus disampaikan kepada anak-cucu, sehingga prinsip-prinsip ini dapat tertanam sejak dini, yang berpengaruh terhadap psikogeografis masyarakat lokal. Berbagai anjuran dan larangan lokal di Desa Watowara, yaitu: Anjuran lokal yang berisikan nasehat-nasehat leluhur meliputi beberapa prinsip yang harus dipegang teguh dalam menjalani hidup dan berinteraksi dengan lingkungan.

Larangan lokal yang ada di Desa Watowara, yaitu larangan untuk menebang pohon, merusak tanaman, memburu dan membunuh binatang, buang air sembarangan di dalam Hutan dan mata air Wailihang serta berbuat asusila di dalam hutan dan mata air Wailihang dan sekitar sumber mata air. Larangan lokal sudah terpatri pada alam pikiran masyarakat Desa Watowara.

Kearifan Lokal Masyarakat Dalam Menjaga Kelestarian Hutan... 
Mitos

Mitos, merupakan salah satu kearifan lokal Desa Watowara dalam pelestarian lingkungan. (hutan, lahan, dan mata air). Mitos diyakini memiliki kekuatan efektif untuk memotivasi masyarakat dalam menjaga kelestarian alam. Mitos yang ada di Desa Watowara terkait menjaga kelestarian hutan dan mata air, yaitu:

(1) Apabila mencuri kayu maka akan dihantui kayu yang dicuri, apabila kayu yang dicuri untuk membangun rumah maka rumah yang dibangun akan roboh.

(2) Apabila merusak tanaman atau mengganggu binatang maka akan diserang sekumpulan tawon, atau disengat oleh sekumpulan lebah.

(3) Apabila buang air sembarangan di sekitar Hutan Waihilang atau di sekitar mata air maka akan jatuh sakit.

(4) Apabila melakukan hal-hal buruk di sekitar Hutan Wailihang dan mata air maka akan mendapat kutukan "kena nitung lolong".

(5) Apabila merusak lingkungan sekitar mata air, maka Anda bingung pulang ke rumah atau hilang, karena mata air yang ada adalah simbol pengorbanan perempuan dari suku tertentu, di dalam Desa, seperti mitos dewi padi (Dewi Sri pada masyarakat Jawa, Tonuwujo pada masyarakat Desa Watowara).

\section{Dampak Kearifan Lokal Masyarakat Desa Watowara}

Kearifan lokal yang dilakukan oleh masyarakat Desa Watowara memberikan dampak positif terhadap kelestarian hutan dan mata air. Dampak yang dirasakan berawal dari tumbuhnya kesadaran masyarakat Desa Watowara untuk menghormati leluhur dan terus mentaati serta tidak mengabaikan nasihat leluhur. Dilihat dari sudut pandang ekologis kearifan lokal berupa upacara adat seperti Baololong, Gletegluok Lewotana yang meliputi rangkaian kegiatan mulai dari gotong-royong membersihkan mata air, membersihkan desa, membersihkan pekarangan rumah, dan memperindah lingkungan dengan melakukan penanaman pohon dapat bermanfaat terhadap kelestarian hutan dan sumber mata air.

Selain itu dengan adanya anjuran dan larangan lokal, serta mitos dirasa cukup efektif sebagai upaya untuk menjaga kelestarian lingkungan karena dapat memberikan arah serta pedoman terhadap kelakuan manusia dalam berinteraksi 
dengan lingkungannya. Melalui bentuk-bentuk kearifan lokal ini, masyarakat Watowara dapat menumbuhkan rasa hormat dan menghargai terhadap objek yang dikeramatkan atau dimitoskan, dalam hal ini adalah Hutan Wailihang, waimatang (mata air), serta flora dan fauna yang ada di sekitarnya. Dampak nyata yang dapat langsung dirasakan dari bentuk-bentuk kearifan lokal yang ada di Desa yaitu masih terjaganya kelestarian hutan, kelestarian flora dan fauna, terjaganya keseimbangan ekosistem di sekitar waimatang Hutan Wailihang, hutan terhindar dari pencurian kayu dan kegundulan hutan, terhindar dari berbagai potensi bencana seperti erosi dan banjir serta keindahan pesona alam yang dapat dirasakan di sekitar Hutan Wailihang.

Kearifan lokal yang ada turut berperan sebagai salah satu upaya konservasi sumberdaya air di Desa Watowara, yang diawali dengan tumbuhnya kesadaran dan tanggungjawab masyarakat terhadap kelestarian alam. Hal ini dibuktikan dengan terciptanya sumber mata air yang bersih dan asri, ketersediaan air yang cukup, debit mata air yang deras sehingga Desa Watowara terhindar dari masalah kesulitan air seperti kekeringan. Selain itu, kebutuhan masyarakat akan air dapat terpenuhi mulai dari kebutuhan air untuk mandi, memasak, minum, dan mencuci. Hal ini di dukung oleh pernyataan Djuwadi (1980), bahwa pemeliharaan hutan sangat berdampak pada kondisi air yang ada di suatu kawasan tertentu karena hutan, tanah, dan air merupakan tritunggal yang tidak dapat dipisahkan, dan justru hutan, tanah dan air inilah komponen-komponen penyusun ekosistem yang dapat dipengaruhi oleh daya manusia.

\section{Kesimpulan}

1. Bentuk kearifan lokal masyarakat Desa Watowara dalam menjaga kelestarian hutan dan mengelola mata air adalah: (1) ritual baololong, (2) upacara gletek glouk Lewotana, (3) upacara Nitung Lolong dan Puduk, dan gemohing. (3) berbagai anjuran dan larangan lokal, dan (4) mitos.

2. Dampak kearifan lokal masyarakat Desa Watowara terhadap kelestarian hutan dan mata air yaitu berawal dari tumbuhnya kesadaran masyarakat Desa Watowara untuk menghormati leluhur dan terus mentaati serta tidak mengabaikan nasihat leluhur. Dampak nyata yang dapat dirasakan meliputi kelestarian hutan yang masih terjaga, kelestarian flora dan fauna, menjaga keseimbangan 
ekosistem di sekitar hutan dan mata air Wailihang, mencegah kegundulan hutan, mengurangi potensi bencana seperti erosi dan banjir, keindahan pesona alam Hutan Wailihang, kebersihan sumber air, ketersediaan air yang cukup serta terhindar dari masalah kesulitan air sehingga kebutuhan masyarakat akan air dapat terpenuhi.

\section{Referensi}

Djuwadi. 1980. Politik Hutan. Yogyakarta: Fakultas Kehutanan Universitas Gadjah Mada

Yunus, Hadi Sabari, 2010, Metodologi Penelitian Wilayah Kontemporer, Yogyakarta: Pustaka Pelajar.

Pemerintah Desa Watowara, 2018, Profil Desa Watowara, Kecamatan Titehena, Lato: Pemerintah Desa Watowara

Sumarmi dan Ach, Amirudin, 2014, Geografi Lingkungan Berbasis Kearifan Lokal, Malang: Aditya.

Singarimbun, M., 2012. Pengumpulan Data Dalam: Metode Penelitian Survei, Edisi Revisi, Effendi, S., dan Tukiran. Eds. Jakarta: LP3ES. 